Check for updates

Cite this: RSC Adv., 2018, 8, 33642

\title{
Mechanism of adsorption of humic acid by modified aged refuse $\dagger$
}

\begin{abstract}
Aiping Zhang, (D)*ab Weiming Chen, ${ }^{c}$ Zhepei Gu, ${ }^{a}$ Qibin Li ${ }^{\mathrm{ac}}$ and Guozhong Shi ${ }^{* b d}$
In the present study, aged refuse (AR) was modified to be applied as an adsorbent to remove humic acid from water. The efficiency of humic acid removal by modified aged refuse (MAR) under different preparation conditions (calcination temperature, dose of aged refuse for calcination and holding time) was systematically investigated. Results showed that the optimum preparation conditions are calcination temperature $=700{ }^{\circ} \mathrm{C}$, AR dose for calcination $=25 \mathrm{~g}$, and holding time $=2.0 \mathrm{~h}$. The characteristics of the modified aged refuse obtained under different calcination conditions were determined by Fourier transform infrared, X-ray diffraction and X-ray photoelectron spectroscopy analysis. In addition, the effects of modified aged refuse dose and initial solution $\mathrm{pH}$ on adsorption performance were studied. The removal of humic acid increased with higher doses of modified aged refuse, and weak alkaline (initial $\mathrm{pH}=8.0$ ) conditions were favorable for humic acid removal. A pseudo-second order model fitted the experimental data well. Moreover, the adsorption isotherms were well described by the Langmuir isotherm model, in which the monolayer surface loading was calculated to be approximately $37 \mathrm{mg} \mathrm{g}^{-1}$. During the adsorption process, the molecular weight, degree of condensation and aromaticity of humic acid were considerably decreased, according to 3D-EEM analysis. MAR as a new type of adsorbent thus provides a potential adsorption method for humic acid.
\end{abstract}

Received 11th July 2018

Accepted 25th September 2018

DOI: 10.1039/c8ra05933k

rsc.li/rsc-advances mutagenicity. Therefore, how to remove humic acid in a water body is a crucial water treatment problem. The main approaches include advanced oxidation processes (AOPs), coagulation, and adsorption. ${ }^{6-8}$

AOPs, especially the ozone method, markedly decrease the concentration of humic acid in water. However, application of AOPs is limited because of several drawbacks, such as the high cost of operation and low utilization of oxidant. ${ }^{9-11}$ Coagulation allows for simple and convenient operation in water treatment, but the unsatisfactory production of organic sludge that must be treated adds to the cost. ${ }^{2,4}$ Comparatively, adsorption is efficient and convenient. There are various adsorbent materials available, ${ }^{\mathbf{1 2}}$ which have different adsorption efficiencies when applied on different adsorbates. Some adsorbents are expensive, thus limiting their use in field applications. Consequently, developing economic adsorbents with high adsorption capacity has become an intensively studied area., ${ }^{\mathbf{6} 3}$

AR is a substance that becomes stable several years after being buried in a landfill. It has a natural multiphase porous structure, high specific surface area, low bulk density, high porosity and high cation exchange capacity. ${ }^{\mathbf{1 4 - 1 6}}$ Given those characteristics, AR is able to adsorb various types of organic matter, ammonia nitrogen and many other pollutants. ${ }^{\mathbf{1 4 , 1 7}}$ Recent studies have reported that AR can considerably alleviate the chemical oxygen demand and ammonia nitrogen concentration in water ${ }^{\mathbf{1 7 - 1 9}}$ and the color number in dye wastewater. ${ }^{20}$ However, the effluents require advanced treatment to meet

\footnotetext{
${ }^{a}$ Key Laboratory of Special Wastewater Treatment of Collages of Sichuan Province, College of Chemistry and Material Science of Sichuan Normal University, Chengdu 610068, China.E-mail: apzhang@sicnu.edu.cn

${ }^{b}$ Laboratory of Development and Application of Rural Renewable Energy, Ministry of Agriculture, Chengdu 610041, China.E-mail: brt666@163.com

${ }^{c}$ Faculty of Geosciences and Environmental Engineering, Southwest Jiaotong University, Chengdu 611756, China

${ }^{d}$ Biogas Institute of Ministry of Agriculture, Chengdu 610041, China

$\dagger$ Electronic supplementary information (ESI) available. See DOI: 10.1039/c8ra05933k
} 
strict discharge standards. With modification by calcination, the physical and chemical structures of MAR can be changed, and the hydrophobicity can be increased, thus increasing the adsorption capacity for humic acid.

On this basis, in this study, AR was modified to adsorb humic acid. We aimed to (1) optimize the preparation conditions of AR modification; (2) determine the characteristics of MAR with different calcination temperatures by using scanning electron microscope-energy dispersive spectroscopy (SEM-EDS), Fourier transform infrared (FTIR) spectroscopy, X-ray diffraction (XRD) and X-ray photoelectron spectroscopy (XPS); (3) investigate the effect of the MAR dose and initial $\mathrm{pH}$ on adsorption performance; (4) evaluate the adsorption properties of MAR through kinetic fitting and correlating the equilibrium data with adsorption isotherm models including the Langmuir and Freundlich isotherm models; (5) determine the transformation of humic acid during the adsorption process, on the basis of three-dimensional fluorescence spectroscopy (3DEEM); and (6) investigate the mechanism of humic acid adsorption on MAR.

\section{Materials and methods}

\subsection{Reagents, AR and water samples}

2.1.1 Reagents. $65 \%$ nitric acid $\left(\mathrm{HNO}_{3}\right)$, hydrochloric acid $(\mathrm{HCl})$, sodium hydroxide $(\mathrm{NaOH})$ and other chemicals from Chengdu Kelong chemical reagent factory were of analytical grade. Humic acid ( $\geq 90 \%$, CAS: $1415-93-6)$ was purchased from Aladdin Co. Ltd., Shanghai, China.

2.1.2 MAR. AR samples used in this experiment were collected from an anaerobic landfill in Southwest China (for 15 years) and screened to $2 \mathrm{~mm}$ in preparation for experiments.

2.1.3 Humic acid solution. Humic acid was dissolved in ultrapure water and diluted to the desired concentration.

\subsection{Preparation of AR adsorbent}

First, AR at different doses (5-30 g) was calcined in ceramic crucibles with covers at the set temperature $\left(200-900{ }^{\circ} \mathrm{C}\right)$ in a muffle furnace. The time for warming up was set according to the rate of temperature increase $\left(10{ }^{\circ} \mathrm{C} \min ^{-1}\right)$ and the target temperature. Second, heat was maintained for certain times (0.5-3 h); the heating was then stopped, and samples were allowed to cool to the ambient temperature. Next, the calcination products were deashed, soaked separately in $5 \% \mathrm{HNO}_{3}$ for $12 \mathrm{~h}$ and rinsed with ultrapure water approximately six times until little nitric acid remained. After being dried in an oven at $105{ }^{\circ} \mathrm{C}$, the $\mathrm{AR}$ adsorbent was used in adsorption experiments.

\subsection{Adsorption experiments}

Certain amounts of AR were added into $100 \mathrm{~mL}$ humic acid solution $\left(100 \mathrm{mg} \mathrm{L}^{-1}\right)$ with a set $\mathrm{pH}$ value. After vibration (150 $\mathrm{rpm}$ ) in a constant temperature vibrator, the reaction mixture was filtered with a $0.45 \mu \mathrm{m}$ glass fiber membrane. Then, the humic acid concentration was measured through detection of ultraviolet adsorption at $254 \mathrm{~nm}$. The adsorption amount $\left(q_{\mathrm{e}}\right)$ and removal rate $(\eta)$ were calculated with eqn (1) and (2), respectively: ${ }^{21}$

$$
\begin{gathered}
q_{\mathrm{e}}=\frac{V\left(c_{0}-c_{\mathrm{e}}\right)}{m} \\
\eta=\frac{c_{0}-c_{\mathrm{e}}}{c_{0}} \times 100 \%
\end{gathered}
$$

where $c_{0}\left(\mathrm{mg} \mathrm{L}^{-1}\right)$ and $c_{\mathrm{e}}\left(\mathrm{mg} \mathrm{L}^{-1}\right)$ represent the initial concentration and equilibrium concentration of humic acid solution; $m(\mathrm{~g})$ represents the dose of adsorbent; and $V(\mathrm{~L})$ represents the volume of humic acid solution.

\subsection{Analytical methods}

2.4.1 Characterization of AR and MAR. The surface morphology of AR and MAR was revealed by SEM-EDS (JSM.5900LV) at $20 \mathrm{kV}$ and $3.0 \mathrm{~nm}$ resolution. Functional groups were determined from FTIR spectra generated with an FTIR spectrophotometer (Bruker VERTEX 70, Germany). XRD spectra were obtained with an X-ray diffractometer (Puxi XD-2, China) operated at $30 \mathrm{kV}$ tube voltage and $40 \mathrm{~mA}$ tube current, using $\mathrm{Cu} \mathrm{K} \alpha$ as radiation source, in $\theta / 2 \theta$ mode.

2.4.2 Determination of humic acid. The adsorbed humic acid solution was filtered, diluted and then detected at $254 \mathrm{~nm}$ on the basis of ultraviolet-visible (UV-vis, Puyuan Alpha 1500, Shanghai, China) spectra. The humic acid concentration was reflected by a linear relationship between the concentration of humic acid and its adsorption, as shown in eqn (3).

$$
y=0.0325 x, R^{2}=0.9987
$$

In addition, to further study the change in aromaticity and degree of condensation of humic acid, 3D-EEM (HORIBA scientific Aqualog-UV-800C, USA) was used and operated at a fixed excited wavelength of $5 \mathrm{~nm}$, a scan speed at 500 $\mathrm{nm} \min ^{-1}$, a range of excitation wavelength of 239-550 $\mathrm{nm}$ and an emission wavelength of 230-650 $\mathrm{nm}$.

\subsection{Adsorption kinetics}

On the basis of the optimum adsorption conditions obtained by the adsorption experiment, the adsorption kinetic characteristics of the process were investigated through detection of the adsorption of humic acid over time. The initial pH of the humic acid solution and the dose of the adsorbent were kept consistent. A pseudo-first-order rate equation (eqn (4)) and pseudosecond-order rate equation (eqn (5)) described the adsorption kinetics of the process, as shown in the following equations. ${ }^{22}$

$$
\lg \left(q_{\mathrm{e}}-q_{t}\right)=\lg q_{\mathrm{e}}-\frac{k_{1} t}{2.303}
$$

$$
\frac{t}{q_{t}}=\frac{1}{k_{2} q_{\mathrm{e}}^{2}}+\frac{t}{q_{\mathrm{e}}}
$$

where $q_{t}\left(\mathrm{mg} \mathrm{g}^{-1}\right)$ is the amount of adsorption of humic acid in solution at time $t ; q_{\mathrm{e}}\left(\mathrm{mg} \mathrm{g}^{-1}\right)$, the equilibrium adsorption capacity, is the amount of adsorption of humic acid in the solution when equilibrium is reached; $k_{1}\left(\mathrm{~min}^{-1}\right)$ is the rate 

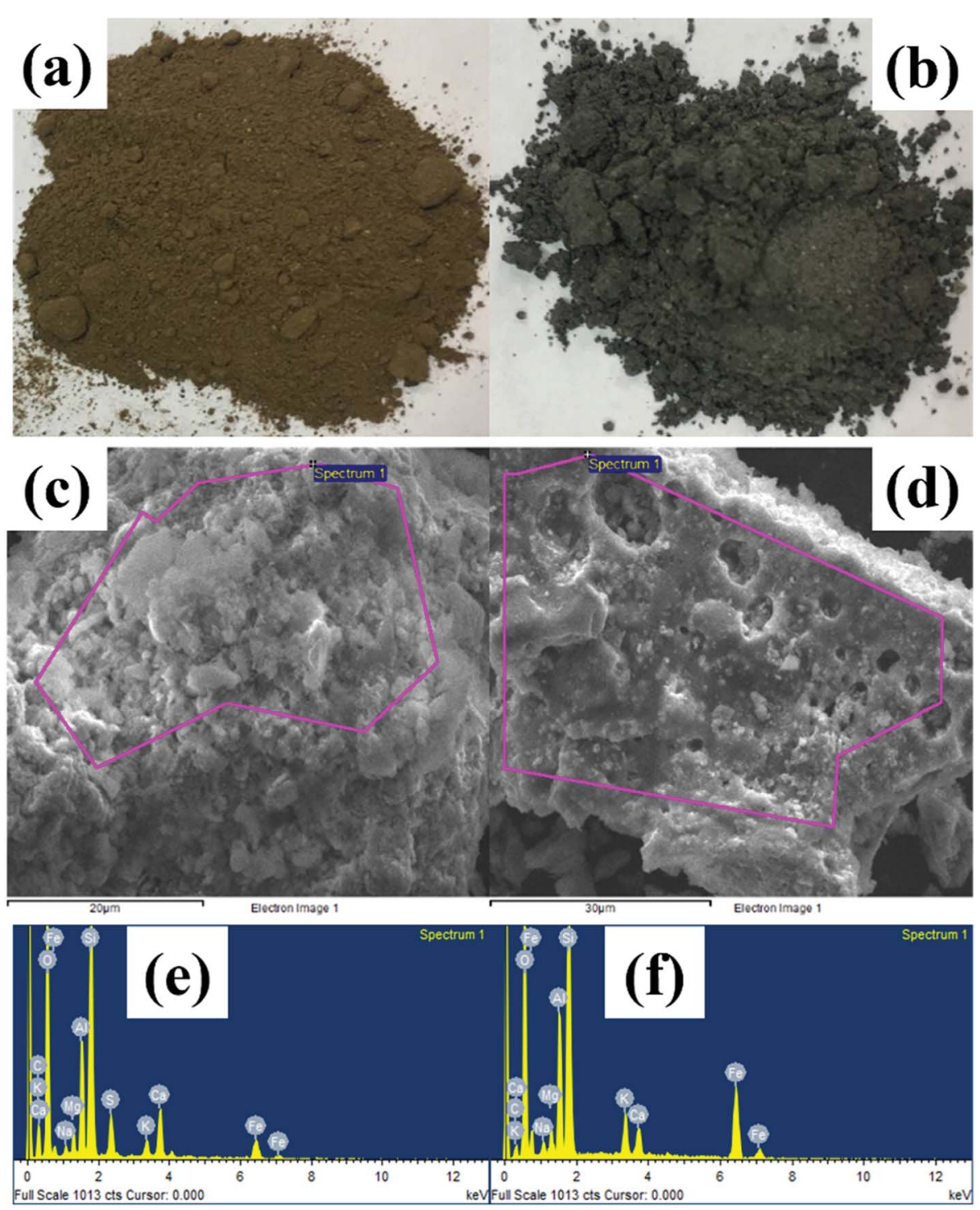

Fig. 1 Pictures of AR (a) before and (b) after modification; SEM-EDS of AR (c) after and (e) before modification; (d) before and ( $f$ ) after modification.

constant of the first-order rate equation; $k_{2}\left(\mathrm{~g}\left(\mathrm{mg}^{-1} \mathrm{~min}^{-1}\right)\right)$ is the rate constant of the second-order rate equation; and $t$ (min) is the reaction time.

\subsection{Adsorption isotherm}

Generally, the dynamic process in which adsorbents adsorb solutes from solutions depends on the equilibrium of adsorption between the solid and liquid phases. Adsorption isotherms are used to describe this process. The most typical of these are the Freundlich (eqn (6)) and Langmuir (eqn (7)) isotherm equations. ${ }^{22,23}$ The adsorption isotherm characteristics of this process were investigated by studying the relationship between the amount of equilibrium adsorption of $\mathrm{AR}$ and the residual amount. This experiment was based on the optimum adsorption conditions for humic acid, which were obtained from adsorption tests. In addition, the amount of added AR and the initial $\mathrm{pH}$ of the humic acid solution were kept constant.

$$
\begin{aligned}
\lg q_{\mathrm{e}} & =\lg k_{\mathrm{f}}+\frac{1}{n} \lg c_{\mathrm{e}} \\
\frac{c_{\mathrm{e}}}{q_{\mathrm{e}}} & =\frac{1}{k_{\mathrm{L}} q_{\mathrm{m}}}+\frac{c_{\mathrm{e}}}{q_{\mathrm{m}}}
\end{aligned}
$$

In the above equations, $k_{\mathrm{f}}$ and $n$ are the Freundlich constants; $k_{\mathrm{L}}$ is the Langmuir constant; and $q_{\mathrm{m}}\left(\mathrm{mg} \mathrm{g}^{-1}\right)$ is the maximum adsorption amount.

\section{Results and discussion}

\subsection{Preparation of AR absorbent}

In this section, the effects of the calcination temperature, AR dose for calcination, and holding time for calcination on the adsorption amount were systematically investigated. The details are shown in ESI.† 


\subsection{Characteristics of AR and MAR}

3.2.1 SEM-EDS analysis. SEM-EDS spectra of AR before and after modification are shown in Fig. 1. SEM indicated a cottonlike surface on the AR material and a microporous surface on the modified material, the latter of which had an improved specific surface area and a more compact carbon skeleton.

EDS revealed abundant metals, such as $\mathrm{C}, \mathrm{O}, \mathrm{Ca}, \mathrm{Fe}, \mathrm{Si}, \mathrm{K}$, and Ti. Non-biodegradable metals are present in municipal solid water; thus, these metals remained in the AR. As shown in Table 1, after modification, the mass percentages of $\mathrm{O}, \mathrm{Fe}, \mathrm{Si}, \mathrm{K}$ and $\mathrm{Al}$ increased, notably by $8.92 \%$ for $\mathrm{Fe}$. These results may be attributable to two aspects: (i) the organic matter in AR underwent combustion and decomposition into carbon dioxide, and sulfates were transformed into gas; (ii) the increase in $(\mathrm{O}+\mathrm{N}) / \mathrm{C}$ ratio suggested that the polarity of the modified material surface increased; ${ }^{\mathbf{2 4 , 2 5}}$ and (iii) because no $\mathrm{N}$ was detected, the increase in $\mathrm{O} / \mathrm{C}$ suggested an enhanced polarity of the modified material surface and a consequently increased capacity to adsorb organic matter.

3.2.2 FTIR and XRD analysis. In Fig. 2(a), the FTIR spectra appear very similar. The peak at $3487 \mathrm{~cm}^{-1}$ reflects the existence of $-\mathrm{OH}$, which might belong to an alcohol or hydroxyl. ${ }^{\mathbf{1 , 2 6 , 2 7}}$ Adsorption at $2924 \mathrm{~cm}^{-1}$ and $1380 \mathrm{~cm}^{-1}$ was caused by $-\mathrm{CH}_{2}^{-}$, thus indicating that some humic acid organic compounds remained during the calcination process. ${ }^{28,29}$ The adsorption at $2924 \mathrm{~cm}^{-1}$ was caused by $\mathrm{C}-\mathrm{H}$ bonds for the same reason. ${ }^{28,30,31}$ The adsorption at $1570 \mathrm{~cm}^{-1}$ and $445 \mathrm{~cm}^{-1}$ was caused by $\mathrm{C}=$ $\mathrm{O}$, thus indicating that the AR included substances such as ketone, ester and carboxylic acid. ${ }^{28,32}$ The intensity of those peaks changed slightly. However, the vibration peak of $\mathrm{C}=\mathrm{O}$ had a red-shift, thus indicating that ether bonded organics stabilized more in the modification process. ${ }^{32,33}$

In Fig. 2(b), the XRD spectrum, in comparison with PDF standard cards, showed a strong diffraction peak at $21^{\circ}, 26.7^{\circ}$, $31.48^{\circ}$ and $50^{\circ}$, thus indicating the presence of high amounts of carbon. We deduced that the material gains some characteristic of carbon substances. In addition, the diffraction peaks at $31.4^{\circ}$, $33.1^{\circ}$ and $59.9^{\circ}$ indicated the existence of ferric oxide. The intensity of the diffraction peaks increased with increasing calcination temperature, thus suggesting there was more ferric oxide after modification.

Table 1 Composition of elements at surface of adsorbent

\begin{tabular}{|c|c|c|c|c|}
\hline \multirow[b]{2}{*}{ Element } & \multicolumn{2}{|c|}{ Raw material } & \multicolumn{2}{|l|}{ Adsorbent } \\
\hline & Weight\% & Atomic\% & Weight\% & Atomic\% \\
\hline CK & 16.83 & 24.40 & 6.11 & 10.22 \\
\hline OK & 54.51 & 59.33 & 50.48 & 63.39 \\
\hline $\mathrm{NaK}$ & 0.55 & 0.42 & 0.94 & 0.82 \\
\hline MgK & 1.23 & 0.88 & 1.22 & 1.01 \\
\hline AlK & 4.28 & 2.76 & 5.93 & 4.41 \\
\hline $\mathrm{SiK}$ & 13.72 & 8.51 & 19.22 & 13.75 \\
\hline SK & 2.02 & 1.10 & - & - \\
\hline $\mathrm{K}$ & 0.90 & 0.40 & 2.39 & 1.23 \\
\hline $\mathrm{CaK}$ & 2.86 & 1.24 & 1.70 & 0.85 \\
\hline FeK & 3.09 & 0.96 & 12.01 & 4.32 \\
\hline Totals & 100.00 & 100.00 & 100.00 & 100.00 \\
\hline
\end{tabular}

3.2.3 XPS analysis. Fig. 3 and Table 2 shows the XPS fitting results of different chemical states of $\mathrm{Fe}, \mathrm{Al}, \mathrm{O}$ and $\mathrm{Si}$ of $\mathrm{AR}$ before and after modification. Fig. 3(a) shows full range scans of the AR and MAR, which contained Fe 2p, Al 2p, O 1s and Si $2 \mathrm{p}$. The details of the chemical states of Fe 2p, Al 2p, O 1s and Si 2p are depicted in Fig. 3(b), (c), (d) and (e), respectively. As shown in Fig. 3(b), three main peaks were located at $710.85 \mathrm{eV}$, $713.71 \mathrm{eV}$ and $724.35 \mathrm{eV}$. Specifically, the peaks located at $710.85 \mathrm{eV}$ and $724.35 \mathrm{eV}$ corresponded to the binding energy of Fe 2p1/2. ${ }^{34-36}$ The peak at $713.71 \mathrm{eV}$ indicated the presence of zero-valent iron. ${ }^{37,38}$ The XPS results of the $\mathrm{Al} 2 \mathrm{p}$ core level are presented in Fig. 3(c). Two peaks were located at $73.71 \mathrm{eV}$ and $74.46 \mathrm{eV}$ for AR, and one peak was located at $74.47 \mathrm{eV}$ for MAR. These peaks corresponded to the binding energy of aluminum oxide. Fig. 3(d) displays the XPS results of the $\mathrm{O}$ 1s core level. Three main peaks were located at $530.89 \mathrm{eV}, 531.76 \mathrm{eV}$ and $532.56 \mathrm{eV}$ for AR. Fig. 3(e) shows the Si 1s core level. Three main peaks were located at $101.94 \mathrm{eV}, 102.60 \mathrm{eV}$ and $103.24 \mathrm{eV}$ for AR, and at $102.10 \mathrm{eV}, 102.63 \mathrm{eV}$ and $103.46 \mathrm{eV}$ for MAR. The three main peaks corresponded to the silicates, thus suggesting that the AR before and after modification contained silicates.

\subsection{Adsorption experiments}

3.3.1 Effects of MAR dose. As shown in Fig. 4(a), with increasing doses of MAR from 0.5 to $10.0 \mathrm{~g} \mathrm{~L}^{-1}$, although the removal rate of humic acid increased from $5.92 \%$ to $99.49 \%$, the adsorption capacity decreased from 24.58 to $10.00 \mathrm{mg} \mathrm{g}^{-1}$. This result might have occurred because with the increase in absorbent dose, the active sites available for adsorption of humic acid may have considerably increased, thus increasing ion and/or proton exchange between active sites and functional groups of humic acid, and consequently increasing the total adsorption of humic acid. ${ }^{39}$ In addition, a possible reason for the slowing humic acid removal rate is that excessive adsorbent may have provided too many adsorption active sites; as the adsorption process continued, the decrease in humic acid concentration may have hindered the chemical adsorption performance of the adsorbent. Thus, the adsorption velocity decreased, and the removal rate of humic acid improved slightly.

3.3.2 Effect of initial pH of solution. As shown in Fig. 4(b), in the range of $\mathrm{pH} 5-10$, with an increase in $\mathrm{pH}$, the equilibrium adsorption amount first increased and then decreased. When the initial pH was increased from 5 to 8 , the adsorption amount increased from $24.40 \mathrm{mg} \mathrm{g}^{-1}$ to $29.18 \mathrm{mg} \mathrm{g}^{-1}$, and the humic acid removal rate increased from $48.17 \%$ to $57.75 \%$. In a weak alkaline solution $(\mathrm{pH} \sim 8)$, the equilibrium adsorption amount reached a maximum. The adsorption process was facilitated by the continuous decrease in $\mathrm{H}^{+}$concentration, thus enhancing the activity of the base groups of AR; therefore, the adsorption effect of humic acid was strengthened. ${ }^{39}$ However, when the $\mathrm{pH}$ increased above 8 , the molecules in humic acid reacted with $\mathrm{OH}^{-}$to form ions, thus enhancing dissolution, hindering molecular adsorption, and decreasing the adsorption amount. 

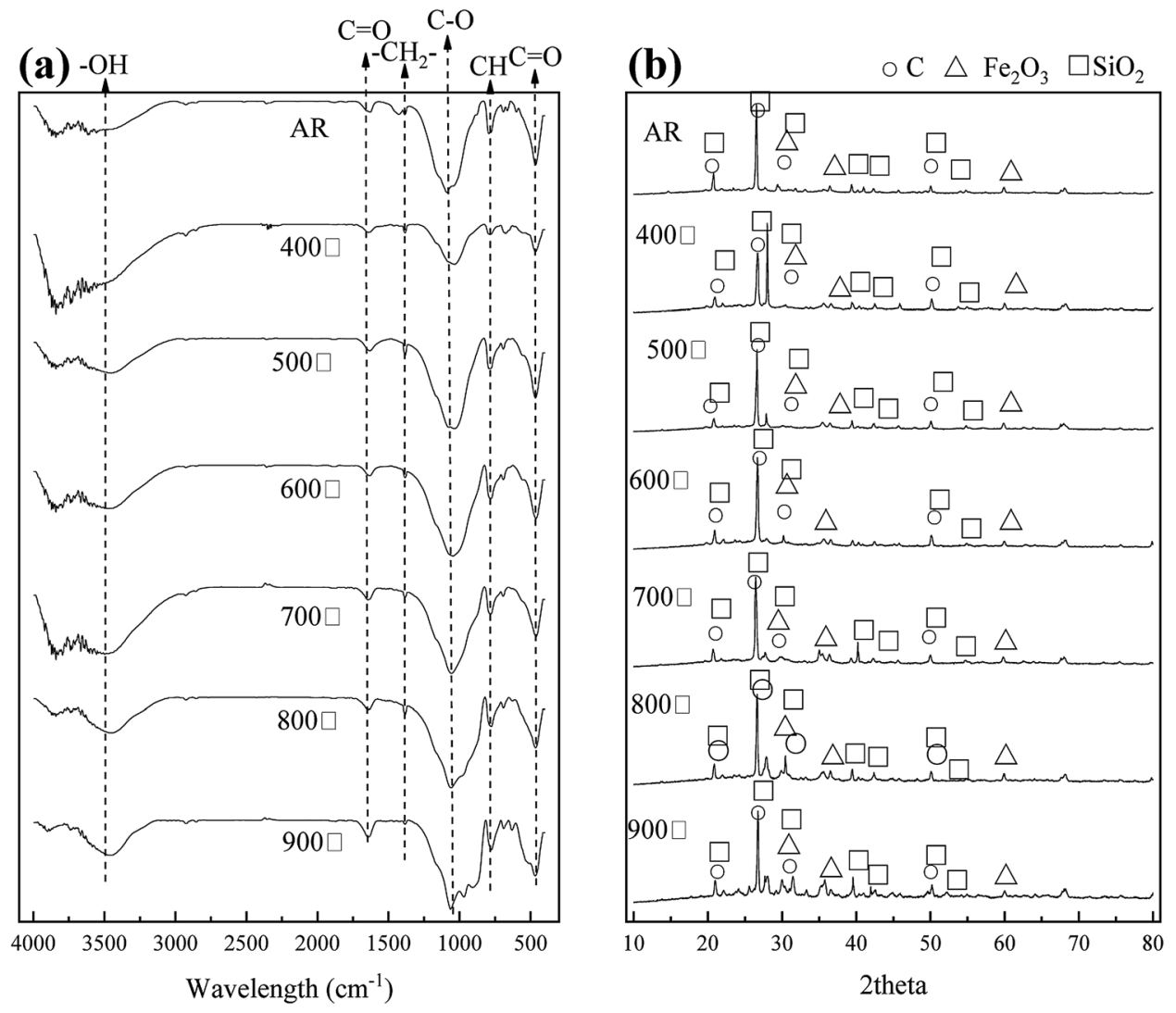

Fig. 2 (a) FTIR and (b) XRD spectra of the AR and MAR calcined under different temperatures.

\subsection{Adsorption isotherm and kinetics}

3.4.1 Adsorption kinetics. As can be seen from Fig. 5(a), as the adsorption gradually progressed, the MAR adsorption reached saturation after $70 \mathrm{~min}$. Before that, with extended reaction time, the humic acid molecules continuously diffused from the surface into the internal pores of the modified adsorbent. The amount of adsorption increased rapidly to $27.07 \mathrm{mg} \mathrm{g}^{-1}$ at $70 \mathrm{~min}$ and became stable (up to $29.18 \mathrm{mg} \mathrm{g}^{-1}$ ) at $120 \mathrm{~min}$. This result may be explained as follows: given the large number of active sites in the MAR, the gradual decrease in the concentration of humic acid and the unoccupied active sites might exacerbate the competitive adsorption of humic acid on the active sites and prolong the adsorption equilibrium time. To investigate the adsorption behavior of humic acid on modified adsorbent, pseudo-first-order and pseudo-second-order kinetics equations of adsorption were applied to fit the data, as shown in Fig. 5(b). In Table 3, the pseudosecond-order kinetics equation $\left(R^{2}=0.9952\right)$ had a higher correlation coefficient than the pseudo-first-order kinetics equation $\left(R^{2}\right.$ $=0.9187)$. The pseudo-second-order kinetic model was more suitable for describing the adsorption kinetics of humic acid on the surface of MAR, thus indicating that chemical adsorption may dominate the adsorption on MAR.

3.4.2 Adsorption isotherm. The experimental data of adsorption amounts under different temperature conditions $\left(25^{\circ} \mathrm{C}\right.$, $30{ }^{\circ} \mathrm{C}$, and $35^{\circ} \mathrm{C}$ ) were fit to Langmuir and Freundlich isotherms.

As shown in Fig. 6 and Table 4, under different temperature conditions, the correlation coefficients of the fitted curves revealed a high level of consistency $\left(R^{2}=0.9998\right)$ in the
Langmuir model and comparative dispersion $\left(R^{2}\right.$ varying from 0.9534 to 0.9951 ) in the Freundlich model. Therefore, the Langmuir model better described the adsorption behavior of humic acid on MAR. Generally, the Langmuir model is suitable for monolayer adsorption. Our results suggest that (1) only one molecule is adsorbed by one active adsorption site, and the surface of the modified mineralization refuse is uniform; (2) there is no interaction between the adsorbed molecules in the layer; and (3) a dynamic balance is achieved between adsorption and resolution. In addition, when the reaction temperature increased, the adsorption amount showed a decreasing trend, thus revealing a spontaneous reaction of humic acid adsorption on MAR.

\subsection{Characterization of humic acid during the adsorption process}

The three-dimensional fluorescence spectrum of humic acid is shown in Fig. 7. The fluorescence data for the humic acid used in the experiment comprise only one peak, which represents the fulvic acid in the ultraviolet region with $E_{\mathrm{x}} / E_{\mathrm{m}}=235-255 / 320-$ $350 \mathrm{~nm}$. This type of fulvic acid arises from organic compounds of low molecular weight and high fluorescence efficiency, and it exists both in landfill leachate and in leachate concentrate in abundance. Its molecular structure is stable, owing to low molecular weight organic matter.

As shown in Fig. 7, with an increase in adsorption time to $90 \mathrm{~min}$, the fluorescence intensity of fulvic acid in the ultraviolet region decreased from 682.36 in the original solution to 302.71. 
(a)

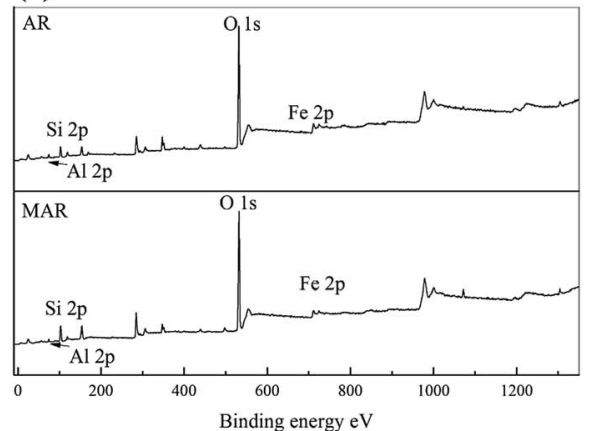

(b)

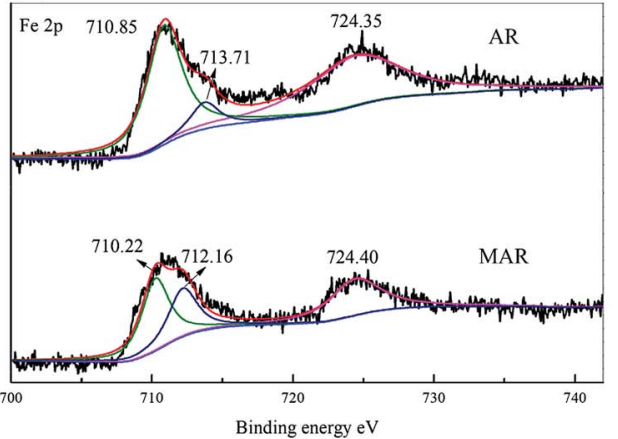

(d)

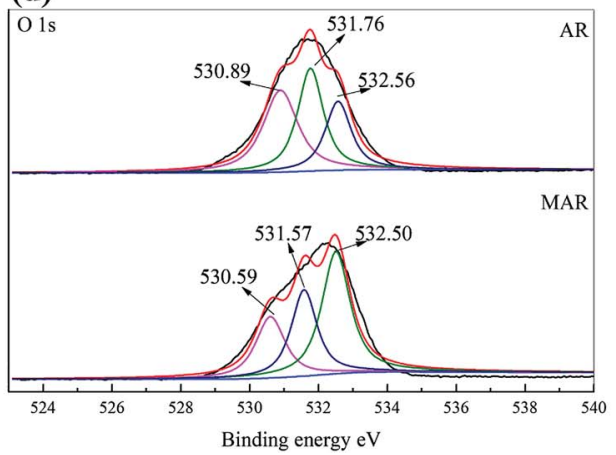

(c)

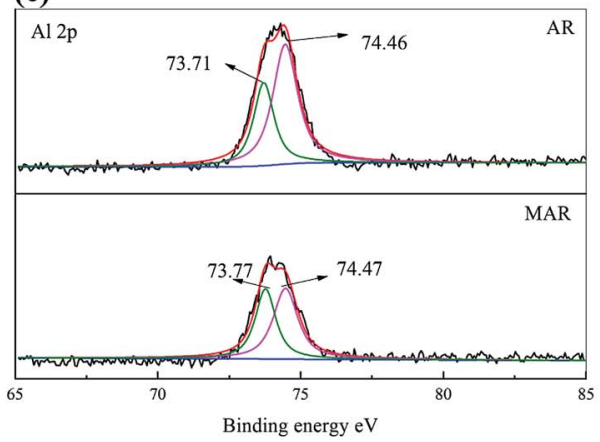

(e)

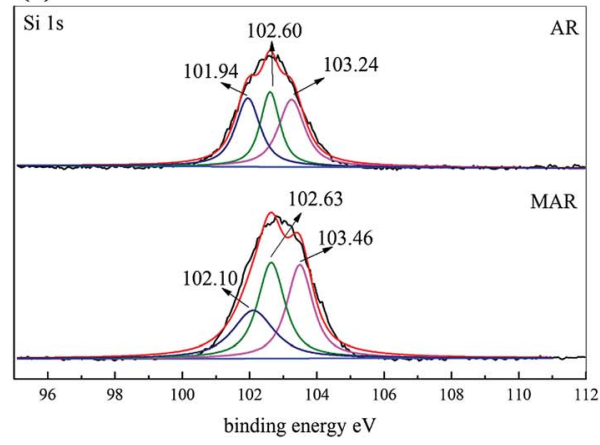

Fig. 3 XPS graphs of AR and MAR: (a) full range scan; (b) Fe 2p; (c) Al 2p; (d) O 1s; (e) Si 1s.

The removal rate of fulvic acid in the ultraviolet region reached $55.64 \%$. However, the location of the fluorescence peak changed slightly, possibly because (1) on the one hand, the amount of carbonyl, aromatic base and other unsaturated groups in the substance of fulvic acid was high in humic acid solution, and remained high in the reaction solution, so the peak strength showed a less obvious decrease; and (2) on the other hand, when the humic acid concentration was low, a blue-shift of the fluorescence peak should appear, but after adsorption, the absorption group would decrease, and a red-shift of the fluorescence peak should be observed. These two effects canceled each other out and resulted in only slight movement of the fluorescence peak.

\subsection{Comparison of different adsorbents for adsorption of humic acid}

A comparison of different adsorbents for adsorption of humic acid was performed, and the conditions and adsorption effects are shown in Table 5.
The adsorption effects of different adsorbents vary greatly, as shown in Table 5 and previous work. For example, Maghsoo$\mathrm{dloo}^{40}$ has used activated carbon (at $25{ }^{\circ} \mathrm{C}$, initial $\mathrm{pH}$ 4) to

Table 2 Variation of binding energy of different elements before and after modification of AR

\begin{tabular}{llll}
\hline Element & Biding energy & AR & MAR \\
\hline $\mathrm{Al}$ & 73.71 & 1549.11 & 896.76 \\
$\mathrm{O}$ & 74.46 & 910.64 & 652.29 \\
& 530.82 & 34236 & 32349 \\
& 531.68 & 41398 & 38821 \\
$\mathrm{Fe}$ & 532.51 & 31564 & 34354 \\
& 710.83 & 9789 & 8015 \\
$\mathrm{Si}$ & 713.59 & 1622 & 2282 \\
& 724.37 & 5098 & 5947 \\
& 101.96 & 2999 & 4199 \\
& 102.66 & 3063 & 4481 \\
& 103.31 & 2416 & 3771
\end{tabular}



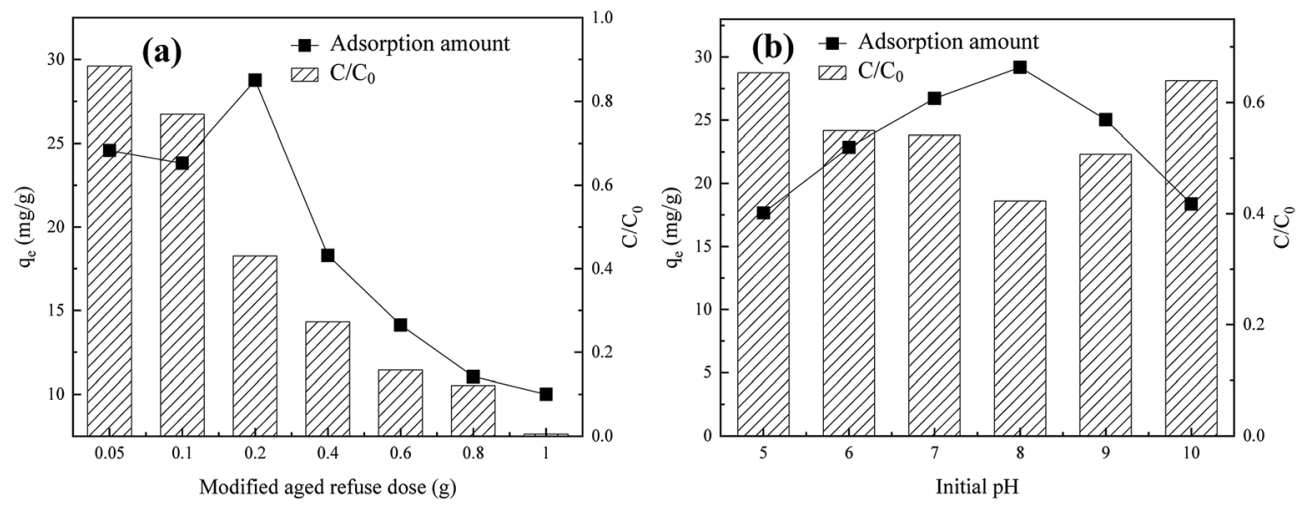

Fig. 4 Effects of (a) adsorbent dose and (b) initial pH of the solution on adsorption performance by MAR.
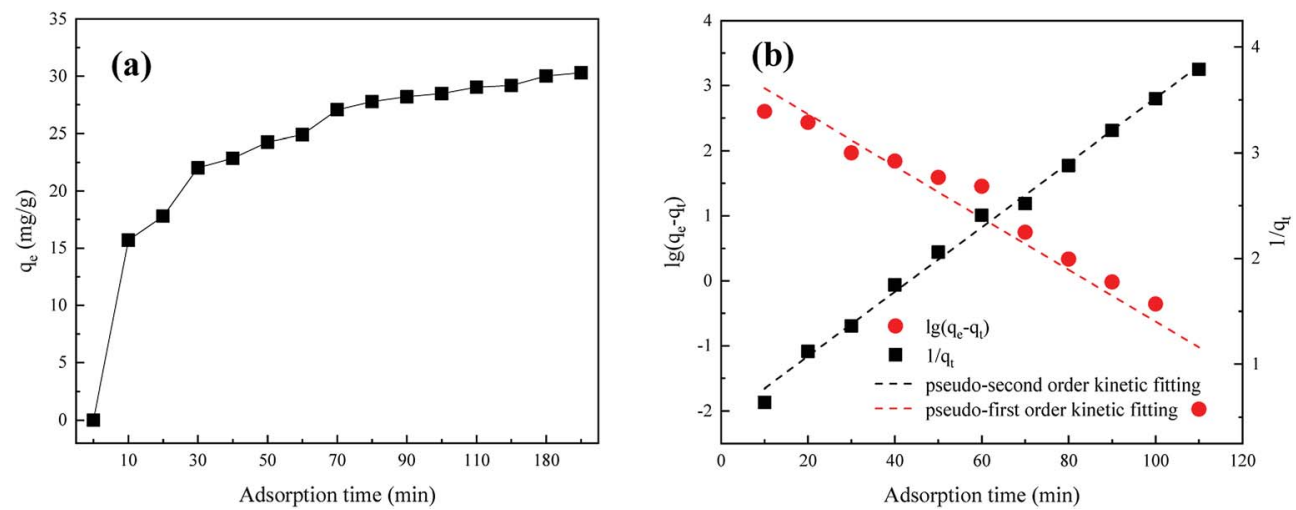

Fig. 5 (a) Adsorption amounts and (b) adsorption kinetics fitting curves.

Table 3 Adsorption kinetics fitting

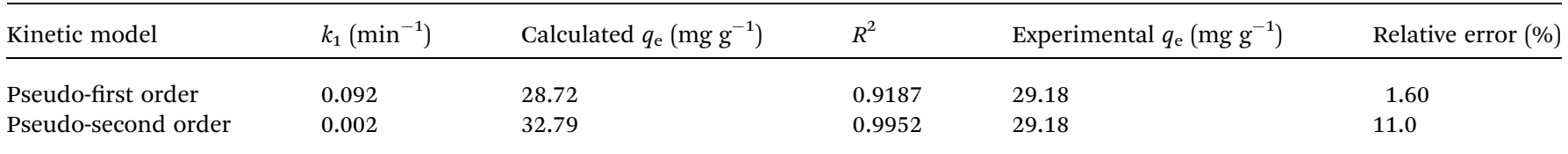
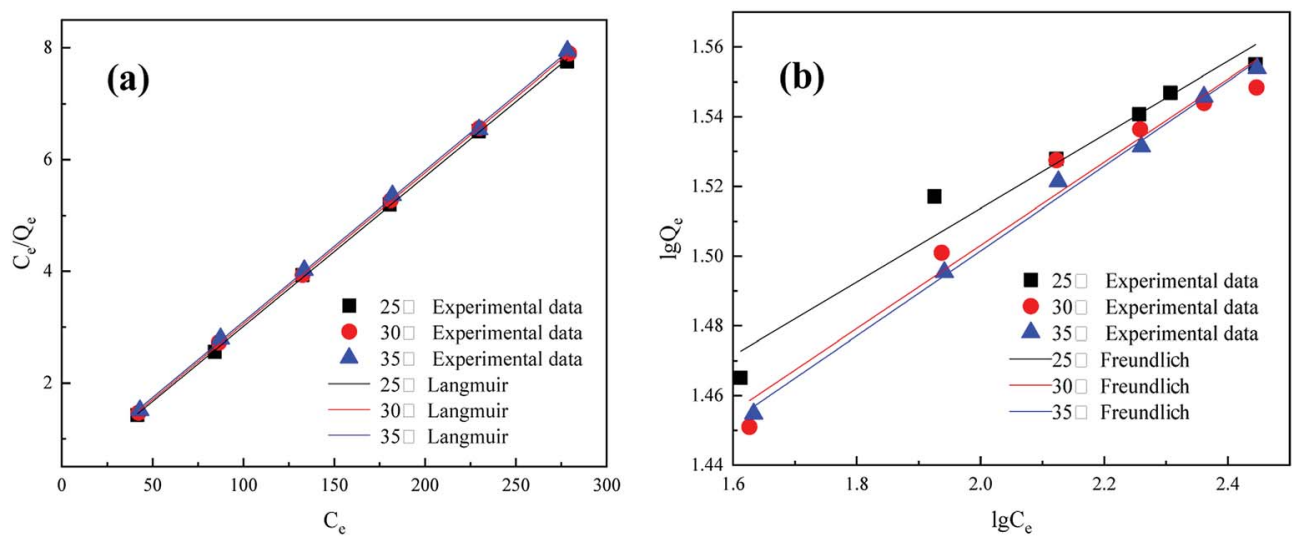

Fig. 6 Adsorption isotherms: (a) Langmuir and (b) Freundlich fitting.

adsorb humic acid and concluded that at the adsorption time of 100 minutes, the adsorption amount was approximately $55.8 \mathrm{mg} \mathrm{g}^{-1}$. Derakhshani ${ }^{1}$ compared the humic acid adsorption performance of bentonite and montmorillonite nanoparticles, which had absorption amounts of 58.21 and $48.20 \mathrm{mg} \mathrm{L}^{-1}$, respectively, under conditions of an initial $\mathrm{pH}$ of 
Table 4 Results of fitting adsorption isotherm

\begin{tabular}{|c|c|c|c|c|c|c|}
\hline \multirow[b]{2}{*}{$\begin{array}{l}\text { Temperature } \\
\left({ }^{\circ} \mathrm{C}\right)\end{array}$} & \multicolumn{3}{|c|}{ Langmuir } & \multicolumn{3}{|c|}{ Freundlich } \\
\hline & $k_{\mathrm{L}}$ & $\begin{array}{l}q_{\mathrm{m}} \\
\left(\mathrm{mg} \mathrm{g}^{-1}\right)\end{array}$ & $R^{2}$ & $k_{\mathrm{f}}$ & $n$ & $R^{2}$ \\
\hline 25 & 0.0817 & 37.3134 & 0.9998 & 22.2255 & 0.1035 & 0.9534 \\
\hline 30 & 0.0766 & 37.0370 & 0.9998 & 18.3738 & 0.1195 & 0.9628 \\
\hline 35 & 0.0700 & 36.9003 & 0.9998 & 18.1009 & 0.1219 & 0.9951 \\
\hline
\end{tabular}

3, a temperature of $25^{\circ} \mathrm{C}$, and an adsorption time of $60 \mathrm{~min}$. $\mathrm{Wu}^{41}$ used quaternary ammonium cationic cellulose (at $44.85{ }^{\circ} \mathrm{C}$, initial $\mathrm{pH}$ 8) to adsorb humic acid and has reported a humic acid adsorption amount of $622 \mathrm{mg} \mathrm{g}^{-1}$ at $120 \mathrm{~min}$. In the present study, AR was modified to improve humic acid adsorption. Under conditions with an initial $\mathrm{pH}$ 8, an adsorption temperature of $25{ }^{\circ} \mathrm{C}$, and an adsorption time of $120 \mathrm{~min}$, the adsorption capacity was $29.18 \mathrm{mg} \mathrm{g}^{-1}$. Although the adsorption amount was lower than those of activated carbon and quaternary ammonium cationic cellulose, the AR materials were inexpensive, thus allowing for extensive application of AR and increasing the utilization rate of resources.

\subsection{Adsorption mechanism of humic acid on MAR}

The physical and chemical characteristics of AR were substantially changed by calcination. The specific surface area and the amount of polar functional groups increased, and the adsorption performance improved. Overall, the mechanisms of adsorption of humic acid on MAR were mainly attributed to two aspects: chemical adsorption and physical adsorption.

Under acid conditions, chemical adsorption is dominant. The carboxyl of humic acid undergoes ion and/or proton exchange reactions with the reactive sites of MAR with hydroxyl groups. Hydroxyl groups on the adsorbent combine with $\mathrm{H}^{+}$in solution, thus resulting in greater hydroxyl group exchange and the formation of $\left(-\mathrm{OH}_{2}^{+}\right)$, according eqn (8). Furthermore, proton exchange reactions occur between $-\mathrm{OH}_{2}{ }^{+}$and the hydroxyl group with outer complexes (eqn (9)). Finally, the inner complex is formed by ligand exchange, according to eqn (10).

$$
\begin{aligned}
& \mathrm{AR}-\mathrm{OH}+\mathrm{H}^{+} \rightarrow \mathrm{AR}-\mathrm{OH}_{2}^{+} \\
& \mathrm{AR}-\mathrm{OH}_{2}^{+}+\mathrm{HA}-\mathrm{C}(\mathrm{O}) \mathrm{O}^{-} \leftrightarrow \mathrm{AR}- \\
& \mathrm{OH}_{2}^{+} \mathrm{O}^{-}-\mathrm{C}(\mathrm{O})-\mathrm{HA}
\end{aligned}
$$
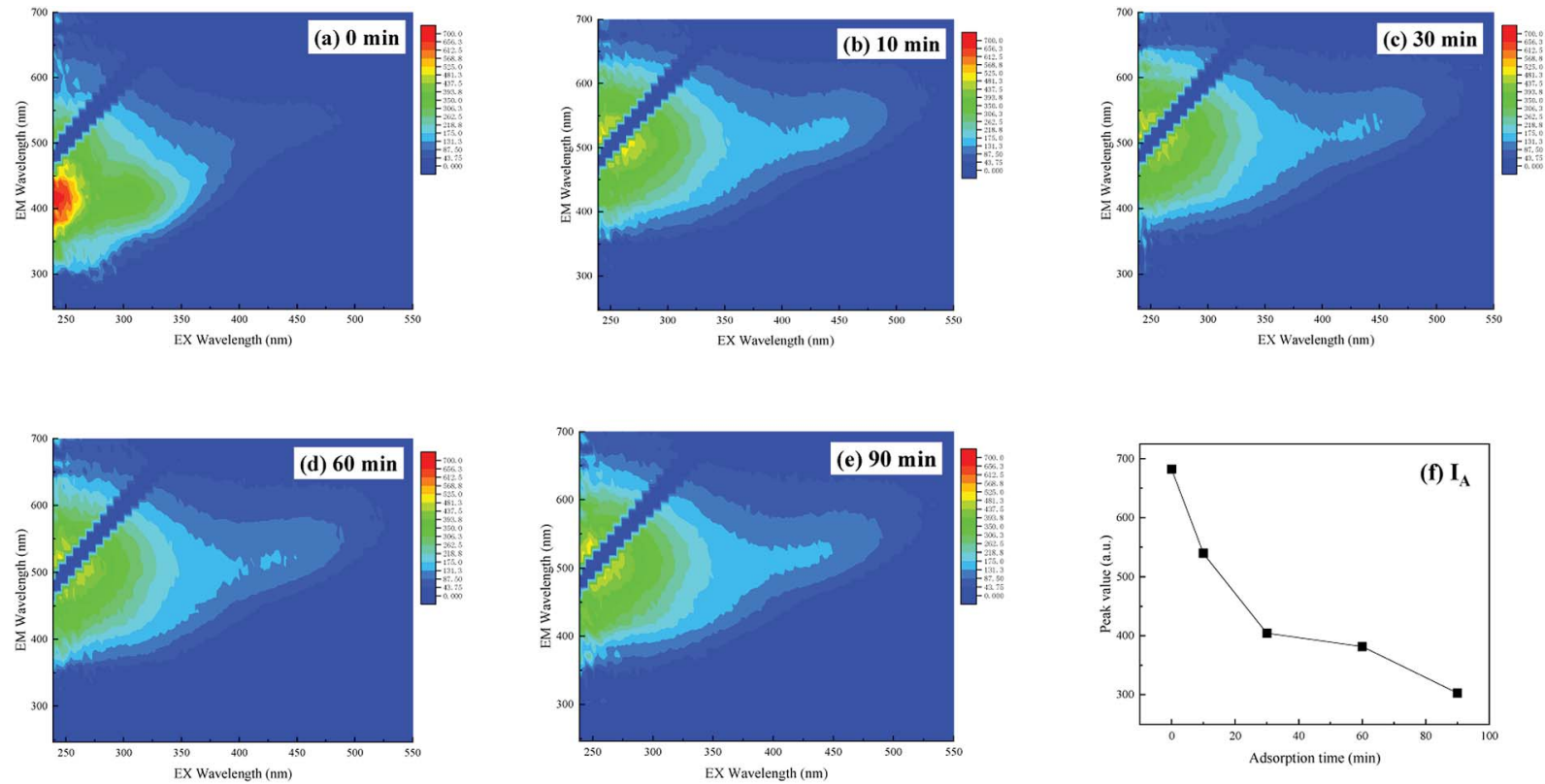

Fig. 7 3D-EEM of humic acid during adsorption of MAR over time: (a) AR humic acid matrix, (b) $10 \mathrm{~min}$, (c) $30 \mathrm{~min}$, (d) $60 \mathrm{~min}$, and (e) $90 \mathrm{~min}$; and

\begin{tabular}{|c|c|c|c|c|}
\hline Adsorbent & Initial $\mathrm{pH}$ & Temperature $\left({ }^{\circ} \mathrm{C}\right)$ & Time (min) & $q_{\mathrm{m}}\left(\mathrm{mg} \mathrm{g}^{-1}\right)$ \\
\hline MAR & 8 & 25 & 120 & 29.18 \\
\hline Granular active carbon $^{36}$ & 4 & 25 & 60 & 55.8 \\
\hline Montmorillonite nanoparticles ${ }^{1}$ & 3 & 25 & 60 & 48.20 \\
\hline Quaternary ammonium type of cationic & 8 & 44.85 & 120 & 622 \\
\hline
\end{tabular}
(f) change in fluorescence peak values over time.

Table 5 Comparison of adsorption amount of humic acid on different adsorbent 


$$
\begin{aligned}
\mathrm{AR}-\mathrm{OH}_{2}^{+} \mathrm{O}^{-}-\mathrm{C}(\mathrm{O})-\mathrm{HA} \leftrightarrow \mathrm{AR}-\mathrm{OC}(\mathrm{O}) \\
-\mathrm{HA}+\mathrm{H}_{2} \mathrm{O}
\end{aligned}
$$

In neutral and weak alkaline conditions, humic acid exhibits substantial proton loss and exists as free ions in solution, thus inhibiting the chemical adsorption to some extent. However, the porous structure of AR, especially after modification, tempers the negative effect via physical adsorption.

\section{Conclusion}

After modification (calcination temperature $=700{ }^{\circ} \mathrm{C}$, AR dose for calcination $=25 \mathrm{~g}$, and holding time $=2.0 \mathrm{~h}$ ), the MAR showed a porous structure, and metal oxides were generated. In addition, the AR before and after modification both contained surface polar functional groups. Under optimum conditions (MAR dose $=2 \mathrm{~g} \mathrm{~L}^{-1}$ and initial $\mathrm{pH}=8.0$ ), the removal rate of humic acid reached $99.49 \%$ at $70 \mathrm{~min}$, and adsorption equilibrium was achieved in approximately $120 \mathrm{~min}$. A pseudosecond order model fit the adsorption kinetics well. The adsorption isotherms were better described by the Langmuir isotherm model, and the monolayer surface loading was calculated to be approximately $37 \mathrm{mg} \mathrm{g}^{-1}$. On the basis of 3DEEM results, humic acid in the solution was efficiently removed. The mechanism of humic acid adsorption by MAR was attributed to two aspects: physical adsorption by a porous structure and chemical adsorption by ions and/or proton exchange between hydroxyl active sites and functional groups of humic acid. Overall, MAR as a new type of adsorbent was demonstrated to be an economical and promising method for humic acid removal from aqueous via adsorption.

\section{Conflicts of interest}

There are no conflicts to declare.

\section{Acknowledgements}

This research was funded by the Agricultural Science and Technology Innovation Program (ASTIP) of Chinese Academy of Agricultural Sciences, the Key Laboratory of Development and Application of Rural Renewable Energy (Ministry of Agriculture) and the Open Foundation of Key Laboratory of Sichuan Province Higher Education System (No. SWWT2015-4).

\section{References}

1 E. Derakhshani and A. Naghizadeh, J. Mol. Liq., 2018, 259, 76-81.

2 P. Jin, J. Song, L. Yang, X. Jin and X. C. Wang, Environ. Pollut., 2018, 233, 290-298.

3 W. Zhang, D. Xie, X. Li, W. Ye, X. Jiang, Y. Wang and W. Liang, Appl. Catal., A, 2018, 559, 75-84.

4 G. Hasani, H. Daraei, B. Shahmoradi, F. Gharibi, A. Maleki, K. Yetilmezsoy and G. McKay, Process Saf. Environ. Prot., 2018, 117, 111-124.
5 V. Oskoei, M. H. Dehghani, S. Nazmara, B. Heibati, M. Asif, I. Tyagi, S. Agarwal and V. K. Gupta, J. Mol. Liq., 2016, 213, 374-380.

6 F.-C. Yang, K.-H. Wu, J.-W. Huang, D.-N. Horng, C.-F. Liang and M.-K. Hu, Mater. Sci. Eng. C., 2012, 32, 1062-1067.

7 V. K. Gupta, R. Kumar, A. Nayak, T. A. Saleh and M. A. Barakat, Adv. Colloid Interface Sci., 2013, 193-194, 2434.

8 D. Robati, B. Mirza, M. Rajabi, O. Moradi, I. Tyagi, S. Agarwal and V. K. Gupta, Chem. Eng. J., 2016, 284, 687-697.

9 O. Turkay, H. Inan and A. Dimoglo, Sep. Purif. Technol., 2014, 134, 110-116.

10 H. Wang, Y. N. Wang, X. Li, Y. Sun, H. Wu and D. Chen, Waste Manag., 2016, 56, 271-279.

11 D. Gumus and F. Akbal, Chemosphere, 2017, 174, 218-231.

12 M. Salman, B. El-Eswed and F. Khalili, Appl. Clay Sci., 2007, 38, 51-56.

13 A. Mittal, J. Mittal, A. Malviya and V. K. Gupta, J. Colloid Interface Sci., 2010, 344, 497-507.

14 Y. Lei, Z. Shen, R. Huang and W. Wang, Water Res., 2007, 41, 2417-2426.

15 C. Xiaoli and Z. Youcai, J. Hazard. Mater., 2006, 137, 410-417. 16 Y. Zhao, Z. Lou, Y. Guo and D. Xu, J. Environ. Manage., 2007, 82, 32-38.

17 H. Li, Y. Gu, Y. Zhao and Z. Wen, J. Environ. Sci., 2010, 22, 1116-1122.

18 Z. Y. Han, D. Liu and Q. B. Li, J. Environ. Manage., 2013, 114, 336-342.

19 C. Wang, Y. Zhao, B. Xie, Q. Peng, M. Hassan and X. Wang, Bioresour. Technol., 2014, 159, 266-271.

20 F.-C. Wu, P.-H. Wu, R.-L. Tseng and R.-S. Juang, J. Taiwan Inst. Chem. Eng., 2014, 45, 2628-2639.

21 T. Yang and M. E. Hodson, Sci. Total Environ., 2018, 635, 1036-1046.

22 Y. Liu, Q. Fan, S. Wang, Y. Liu, A. Zhou and L. Fan, Chem. Eng. J., 2016, 306, 174-185.

23 Q. Yin, H. Ren, R. Wang and Z. Zhao, Sci. Total Environ., 2018, 631-632, 895-903.

24 W. Huang and B. Chen, J. Environ. Sci., 2010, 22, 1586-1594.

25 X. Zhu, B. Chen, L. Zhu and B. Xing, Environ. Pollut., 2017, 227, 98-115.

26 J. Cao, Z. Xiong, Y. Yuan, B. Lai and P. Yang, $R S C A d v ., 2016$, 6, 94467-94475.

27 Z. Droussi, V. D'Orazio, M. R. Provenzano, M. Hafidi and A. Ouatmane, J. Hazard. Mater., 2009, 164, 1281-1285.

28 X. Guo, X. He, H. Zhang, Y. Deng, L. Chen and J. Jiang, Microchem. J., 2012, 102, 115-122.

29 H. C. Kim and M. J. Yu, Water Res., 2005, 39, 4779-4789.

30 M. Jayapal, H. Jagadeesan, M. Shanmugam, J. P. Danisha and S. Murugesan, J. Hazard. Mater., 2018, 354, 231-243.

31 S. N. Malik, P. C. Ghosh, A. N. Vaidya and S. N. Mudliar, J. Hazard. Mater., 2018, 357, 363-375.

32 X. S. He, B. D. Xi, Z. Y. Zhang, R. T. Gao, W. B. Tan, D. Y. Cui and Y. Yuan, J. Hazard. Mater., 2015, 283, 227-233.

33 V. Kanokkantapong, T. F. Marhaba, B. Panyapinyophol and P. Pavasant, J. Hazard. Mater., 2006, 136, 188-196. 
34 J. Fan, L. Gu, D. Wu and Z. Liu, Chem. Eng. J., 2018, 333, 657664.

35 X. Pan, L. Yan, C. Li, R. Qu and Z. Wang, Chem. Eng. J., 2017, 326, 1197-1209.

36 J. Wang, Y. Ding and S. Tong, Sep. Purif. Technol., 2017, 184, 365-373.

37 F. Ji, H. Yin, H. Zhang, Y. Zhang and B. Lai, J. Cleaner Prod., 2018, 188, 860-870.
38 J. Li, Q. Ji, B. Lai and D. Yuan, J. Taiwan Inst. Chem. Eng., 2017, 80, 686-694.

39 E. M. Murphy, J. M. Zachara, S. C. Smith and J. L. Phillips, Sci. Total Environ., 1992, 117, 413-423.

40 S. Maghsoodloo, B. Noroozi, A. K. Haghi and G. A. Sorial, J. Hazard. Mater., 2011, 191, 380-387.

41 W. Wei, S. Wenjian, W. Jingzhi and Y. Qinlin, Chin. J. Inorg. Chem., 2014, 30, 2057-2063. 